\title{
EDITORIAL
}

\section{The challenge of neuro intensive care units}

Patients with neurological pathologies or severe neurosurgeries, have always received care in general intensive care units. However, with the need for intensive care in patients during postoperative craniotomies and spinal surgery, neurosurgical intensive care units began to emerge. Because of this characteristic of caring for the neurosurgical patient, other patients were hospitalized with diagnoses of cerebral trauma, spinal cord injury, cerebral vascular accident, poor epileptic condition, encephalitis, and severe neuromuscular disease.

Over the past 30 years, neuro intensive care has been growing as a specialty, with various neurological intensive care units worldwide and in $\mathrm{Brazil}^{(1,2,3)}$. In 2002, the international and multidisciplinary neurocritical care society was created (www.neurocriticalcare.org) and in 2004, the first journal dedicated to neurocritical care was published, the Neurocritical Care Journal.

The care of the neurocritical patient is provided by a multiprofessional team trained and specialized to recognize and deal with patients, often in situations of risk for irreversible neurological injury or brain death. Generally, this team consists of a physician, nurse, physiotherapist, occupational therapist, speech therapist, psychologist and nutritionist. The impact of this team is to improve the patient's functioning, decreasing the length of stay in the neurologic intensive care unit, reducing mortality and the use of hospital resources ${ }^{(4,5)}$.

With advancement in technology, neurocritical patient monitoring is no longer restricted to the neurological examination, the computerized tomography examination, monitoring of intracranial pressure or of the cerebral perfusion pressure. Increasingly, the trend is for the multimodal neuro-monitoring, in an invasive or non-invasive manner, with transcranial doppler, continuous electroencephalogram, cerebral blood flow, core and cerebral temperature, partial pressure of $\mathrm{O}_{2}$ of the cerebral tissue, and microdialysis ${ }^{(6)}$. The complexity of the neurocritical patient, coupled with various forms of neurological monitoring, requires technical and scientific knowledge of the multidisciplinary team, with a direct impact on the quality of care.

In Brazil, in recent years, both educational institutions as well as specialty societies have mobilized for the development of professional training, through refresher or postgraduate courses, or conferences in neurointensive care. However, there is a shortage of these professionals in neurocritical patient care, which is one of the great challenges for neurointensive care units. 


\section{References}

1. Howard RS, Kullmann DM, Hirsch NP. Admission to neurological intensive care: who, when, and why? J Neurol Neurosurg Psychiatry. 2003; 74(Suppl 3): iii2-iii9.

2. Bleck TP. Historical aspects of critical care and the nervous system. Crit Care Clin. 2009; 25(1):153-64.

3. Domingues JR, Manno E. Brazilian neurointensive care: a brief history. Arq Bras Neurocir. 2011; 30(4):166-8.

4. Suarez JI, Zaidat OO, Suri MF, Feen ES, Lynch G, Hickman J, et al. Length of stay and mortality in neurocritically ill patients: Impact of a specialized neurocritical care team. Crit Care Med. 2004; 32:2311-17.

5. Varelas PN, Eastwood D, Yun HJ, Spanaki MV, Hacein Bey L, Kessaris C, et al. Impact of a neurointensivist on outcomes in patients with head trauma treated in a neurosciences intensive care unit. J Neurosurg. 2006;104:713-19.

6. Oddoa M, Villab F, Citeriob G. Brain multimodality monitoring: an update. Curr Opin Crit Care. 2012; 18:111-8.

\section{Solange Diccini}

Nurse. Associate Professor, Paulista School of Nursing, Federal University of São Paulo

(Escola Paulista de Enfermagem da Universidade Federal de São Paulo - UNIFESP) 